\title{
Cri-du-chat syndrome mimics Silver-Russell syndrome depending on the size of the deletion: a case report
}

\author{
Yerai Vado ${ }^{1,2}$, Javier Errea-Dorronsoro ${ }^{1}$, Isabel Llano-Rivas ${ }^{3}$, Nerea Gorria ${ }^{4}$, Arrate Pereda', Blanca Gener ${ }^{3}$, \\ Laura Garcia-Naveda ${ }^{3}$ and Guiomar Perez de Nanclares ${ }^{1 *}$ (iD
}

\begin{abstract}
Background: Silver-Russell Syndrome (SRS) is a rare growth-related genetic disorder mainly characterized by prenatal and postnatal growth failure. Although molecular causes are not clear in all cases, the most common mechanisms involved in SRS are loss of methylation on chromosome 11 p15 ( $50 \%)$ and maternal uniparental disomy for chromosome 7 (upd(7)mat) $(\approx 10 \%)$.
\end{abstract}

Case presentation: We present a girl with clinical suspicion of SRS (intrauterine and postnatal growth retardation, prominent forehead, triangular face, mild psychomotor delay, transient neonatal hypoglycemia, mild hypotonia and single umbilical artery). Methylation and copy number variations at chromosomes 11 and 7 were studied by methylationspecific multiplex ligation-dependent probe amplification and as no alterations were found, molecular karyotyping was performed. A deletion at 5p15.33p15.2 was identified (arr[GRCh37] 5p15.33p15.2(25942-11644643)×1), similar to those found in patients with Cri-du-chat Syndrome (CdCS). CdCS is a genetic disease resulting from a deletion of variable size occurring on the short arm of chromosome 5 (5p-), whose main feature is a high-pitched mewing cry in infancy, accompanied by multiple congenital anomalies, intellectual disability, microcephaly and facial dysmorphism.

Conclusions: The absence of some CdCS features in the current patient could be due to the fact that in her case the critical regions responsible do not lie within the identified deletion. In fact, a literature review revealed a high degree of concordance between the clinical manifestations of the two syndromes.

Keywords: Silver-Russell syndrome, Cri-du-chat syndrome, aCGH, Deletion

\section{Background}

Silver-Russel Syndrome (SRS, OMIM\#180860) is a rare genetic imprinting disorder, initially described as an heterogeneous phenotype including intrauterine (IUGR) and postnatal growth retardation (PNGR) without catch-up growth, relative macrocephaly at birth, triangular face, body asymmetry, facial dysmorphic features and severe feeding difficulties $[1,2]$. More recent case reports have led to the inclusion of low body mass index, hypoglycemia, motor and speech delay and psychosocial challenges as additional features (for a review, [3]). The incidence of the disease is not clear, reported estimates

\footnotetext{
* Correspondence: gnanclares@osakidetza.eus

${ }^{1}$ Rare Diseases Research Group. Molecular (Epi)Genetics Laboratory, BioAraba Health Research Institute, OSI Araba University Hospital, Vitoria-Gasteiz, Araba, Spain
} Full list of author information is available at the end of the article varying from $1 / 100,000$ to $30 / 100,000$ [3, 4]. Most cases of SRS are sporadic, with a low rate of familial cases that have been suggested to follow an autosomal dominant transmission pattern [5].

The wide variability of the clinical manifestations of SRS has led to the international recommendation to use the Netchine-Harbison SRS clinical scoring system (NH-CSS) [6], both for determining when SRS genetic testing should be run and when a clinical diagnosis of SRS should be given [3]. Although studies have failed to determine the underlying molecular mechanism in some cases, approximately $50 \%$ of the clinically-diagnosed SRS patients present alterations at $11 \mathrm{p} 15.5$, mainly hypomethylation at H19/IGF2:IG-DMR, while $10 \%$ of them show maternal uniparental disomy of chromosome 7 (upd(7)mat) [3]. In addition, there have been reports of a

(c) The Author(s). 2018 Open Access This article is distributed under the terms of the Creative Commons Attribution 4.0 International License (http://creativecommons.org/licenses/by/4.0/) which permits unrestricted use, distribution, and reproduction in any medium, provided you give appropriate credit to the original author(s) and the source, provide a link to the Creative Commons license, and indicate if changes were made. The Creative Commons Public Domain Dedication waiver (http://creativecommons.org/publicdomain/zero/1.0/) applies to the data made available in this article, unless otherwise stated. 
single maternally-transmitted $C D K N 1 C$ activating mutation in five members of a four-generation family [7] and paternal IGF2 inactivating mutations in another family and four unrelated patients [8-10]. Further, sequence variants of two non-imprinted genes (HMGA2 and PLAG1) are also associated with SRS. Specifically, $H M G A 2$ variants have been described in one family and two sporadic cases [11, 12] and PLAG1 mutations in a family and in one sporadic case [11]. For the remaining $40 \%$ of SRS patients who are negative for these alterations, molecular karyotyping is advised [3, 13, 14]. Two recent reviews have compiled all the reported chromosomal regions involved in SRS-like cases and suggested that the most frequently affected is $12 \mathrm{q} 14$, followed by $1 \mathrm{q} 21,4 \mathrm{p} 16.3,15 \mathrm{q} 26,17 \mathrm{p} 13.3$ and 22q11 $[9,15]$.

\section{Case presentation}

The CARE guidelines were followed in reporting this case.

\section{Case report}

We present the case of a girl who is the third child of healthy non-consanguineous parents. A prenatal ultrasound test revealed a single umbilical artery with no other malformations. She was born at term, by vaginal delivery after induction due to fetal hypomobility, with a birth weight of $2450 \mathrm{~g}(p<1)$, birth length of $47 \mathrm{~cm}(\mathrm{p} 3)$, and cranial perimeter of $33 \mathrm{~cm}$ (p10). No perinatal diseases were detected, except for one episode of transient neonatal hypoglycemia. In the neonatal period, no abnormal cry was noticed. She was monitored closely because of postnatal growth retardation in the absence of familial short stature (father's height $180 \mathrm{~cm}$, mother's height $158 \mathrm{~cm}$ ). At 22 months of age, she was referred for brain magnetic resonance imaging because of neurodevelopmental delay, and Arnold Chiari malformation type I and corpus callosum hypoplasia with mild ventriculomegaly were identified. A peculiar face with triangular shape was observed and height $(78.5 \mathrm{~cm}, \mathrm{p} 3)$ and weight $(9.7 \mathrm{~kg}, \mathrm{p} 7)$ were still delayed. Generalized hypotonia was still present. Surgery for Arnold Chiari I was performed, and subsequently, her motor development slightly improved. At the age of $4^{9 / 12}$, she was referred for clinical genetic assessment and SRS was suspected with a score of 4/6 on the NH-CSS: including IUGR, PNGR, prominent forehead and triangular face (Fig. 1a). At this age, she had a weight of $14.4 \mathrm{~kg}(\mathrm{p} 7)$, a height of $99.5 \mathrm{~cm}$ (p2) and a cranial perimeter of $49 \mathrm{~cm}$ (p15). Phenotypically, she also presented craniofacial disproportion, wide normal set rotated ears, a triangular face, large eyes and narrow nasal bridge (Fig. 1a), as well as small feet and hands with quadrangular fingertips (Fig. 1b). The 5th finger on each hand was shortened without clinodactyly (Fig. 1b); the great toe of each foot was wide and she had bilateral diastasis between the first and second toes. She also had a very smooth non-nasal voice.

\section{Molecular genetic studies}

Genomic DNA was extracted from peripheral blood leukocytes using a commercial kit, following the manufacturer's instructions (QiaAmp Blood Mini, Qiagen, Düren, Germany). Dosage and methylation analyses for chromosomes 11 and 7 were carried out by methylation-specific multiplex ligation-dependent probe amplification using the ME030-C3 and ME032-A1 kits, respectively (MRC-Holland, Amsterdam, The Netherlands) following the manufacturer's recommendations. No alterations in methylation or copy number variations $(\mathrm{CNV})$ were detected in either of these regions.

Subsequently, molecular karyotyping was performed using a $400 \mathrm{~K}$ microarray-based comparative genomic hybridization (aCGH) kit (G4448A, Agilent Technologies, Santa Clara, CA, USA). Slides were scanned on an Agilent SureScan C Microarray scanner and analyzed with Agilent CytoGenomics software, revealing a deletion on the short arm of chromosome 5, specifically at 5p15.33p15.2 (arr[GRCh37] 5p15.33p15.2(25942-11644643)×1) (Fig. 2),
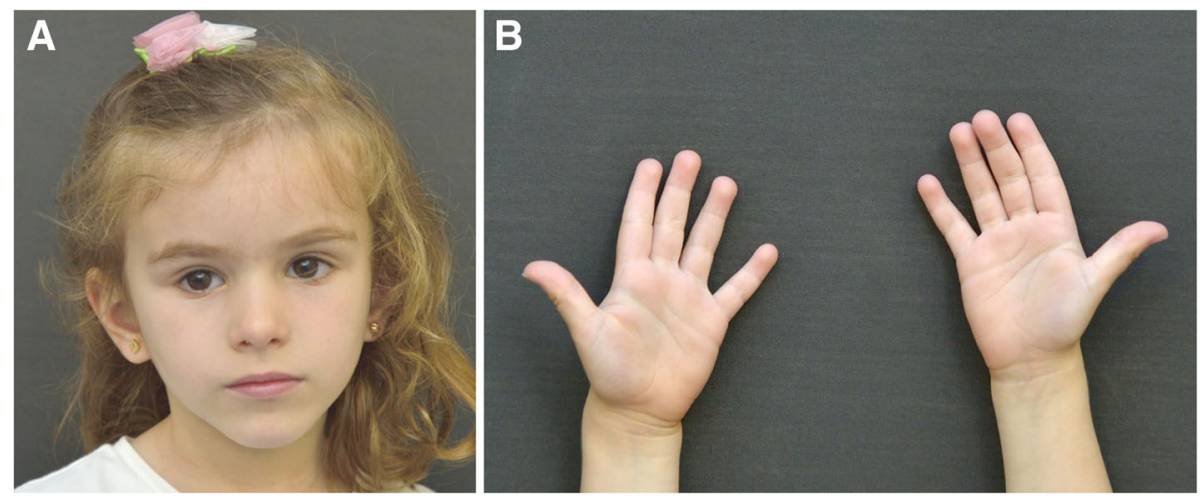

Fig. 1 Clinical photograph of the patient. a: Front view of the face. Note the prominent forehead, triangular face, large eyes and narrow nasal bridge. $\mathbf{b}$ : Palmar view of the hand showing the small size and quadrangular fingertips 


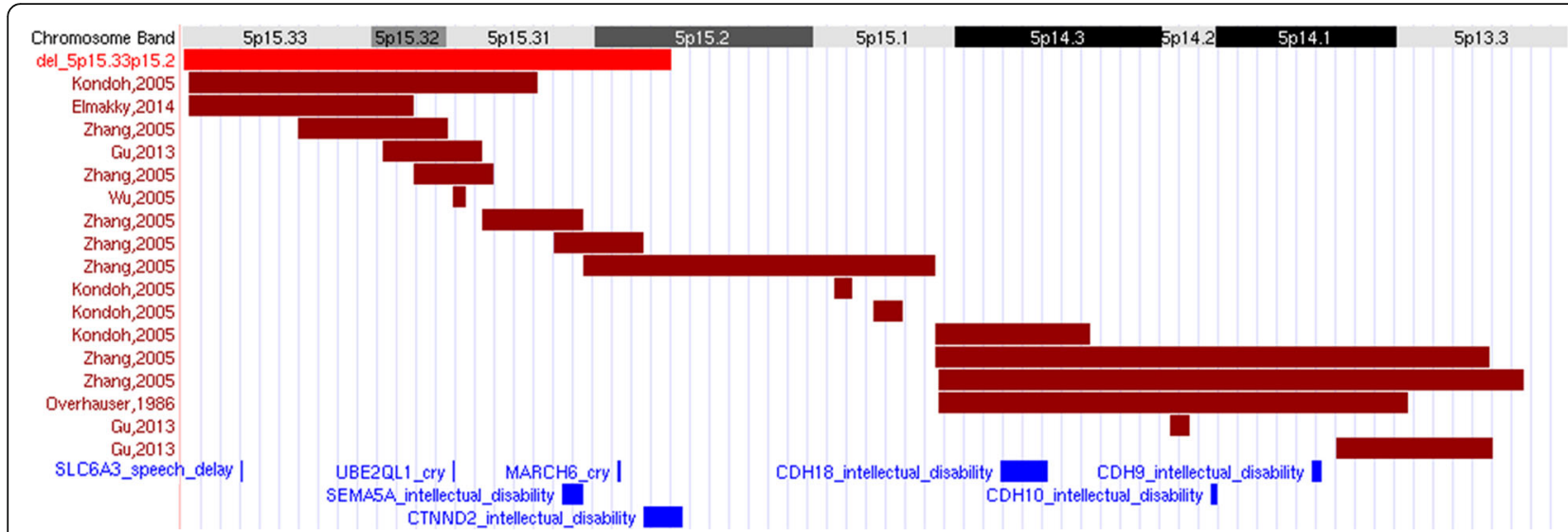

Fig. 2 Schematic view of the short arm of chromosome 5, showing some described deletions and genes important in CdCS. The red bar at the top shows the deletion in the patient. Garnet bars are an indication of approximate regions deleted in several different patients described in literature, based on a recent review [35]. Some of the genes associated with the important features of CdCS are highlighted in blue

within the region usually associated with Cri-du-chat syndrome $(\mathrm{CdCS})$.

Fluorescence in situ hybridization (FISH) analyses were performed on metaphase cells and interphase nuclei using a Vysis CSF1R/D5S23, D5S721 FISH Probe Kit to confirm the presence of the deletion and its origin. The results showed one green signal (5p15) and two red signals (CSF1R probe) in the metaphases and nuclei of the index corresponding to a deletion of the 5 p15 region (Additional file 1 Figure S1A, $\mathrm{B})$, confirming the aCGH results. In accordance with the 2016 edition of the International System for Human Cytogenomic Nomenclature, the patient's karyotype can be described as 46,XX,del(5)(p15.2).ish $\operatorname{del}(5)(\mathrm{p} 15.2)(\mathrm{D} 5 \mathrm{~S} 23-$, D5S721-). The FISH pattern on chromosome 5 was normal in both parents $(2 \mathrm{G} 2 \mathrm{R})$, confirming the de novo nature of the deletion (Additional file 1 Figure S1C-F).

\section{Clinical re-evaluation}

A literature review showed us that there are some clinical features which are common to CdCS and SRS (Table 1). Keeping the results of this review and the genetic analysis in mind, clinical re-evaluation at 5 years 6 months of age confirmed some features suggestive of SRS (failure to thrive, retarded postnatal growth [height $104.5 \mathrm{~cm}$ (p4), weight $15.2 \mathrm{~kg}$ (p9), cranial perimeter $49.2 \mathrm{~cm}$ (p12)], prominent forehead) and some others of CdCS (slightly prominent chin with micrognathia); however, she did not have lip, palatal or mouth alterations; small hands with thin and long fingers; sandal gap deformity; or clinodactyly. The neurodevelopmental study revealed that she has not achieved the milestones for her chronological age (sitting without support and crawling at 12 months; walking independently at 25 months; very poor speech and verbal development with just 5-10 words at 2 years; and at the time of writing she still has neither bowel nor bladder control, is not able to read or write, and lacks fine motor skills). She is receiving psychological and learning support at school. She also has a high-pitched voice and dysphonia (possibly due to a defect in the larynx with vocal fold atrophy).

\section{Discussion and conclusions}

Sometimes, clinical diagnosis of patients with syndromic manifestations is challenging due to either an absence of cardinal features or an overlap of characteristics between different disorders or a combination of both.

It is known that CdCS (OMIM\#123450) is caused by deletions of heterogeneous size in the short arm of chromosome 5 [16]. Even though it is considered a rare disease, CdCS is one of the most common chromosomal deletion syndromes with an incidence ranging from $1: 15,000$ [17] to $1: 50,000$ live births [18]. In more than $80 \%$ of cases, the deletion is found to be de novo [19] and its extension seems to be closely related to the presence of certain phenotypic features [20].

The main clinical features at birth are: plaintive high-pitched monochromatic cry similar to the mewing of a cat (95.9\%), which disappears after the neonatal period; microcephaly (mean head circumference, $31.8 \mathrm{~cm}$ ) and low weight (mean weight, $2614 \mathrm{~g}$ ). Other notable characteristics are: rounded face (83.5\%), broad nasal bridge (87.2\%), hypertelorism (81.4\%), epicanthal folds (90.2\%), downslanting palpebral fissures (56.9\%), low-set ears (69.8\%), micrognathia (96.7\%), abnormal dermatoglyphics (92\%), hypotonia and down-turned corners of the mouth (81.0\%) [21]. CdCS patients also show severe psychomotor and intellectual disability, high palatal arch [20], speech delay, prenatal and postnatal growth delay, and low-set and/or poorly formed pinnae [22]. 
Table 1 Clinical characteristics of Silver-Russell Syndrome (SRS) (Wakeling et al., 2017 [3]) and Cri-du-Chat Syndrome (CdCS) (Cerruti Mainardi, 2006 [21]; D M Church et al., 1995 [20]; D M Church et al., 1997 [22]) together with features observed in our patient

\begin{tabular}{|c|c|c|}
\hline SRS & CdCS & Patient \\
\hline$\underline{\text { IUGR }}$ & $\underline{\text { IUGR }}$ & IUGR \\
\hline PNGR & PNGR & PNGR \\
\hline Speech delay & Speech delay & Speech delay \\
\hline Motor delay & Motor delay & Motor delay \\
\hline Hypotonia & Hypotonia & Hypotonia \\
\hline Mild intellectual delay & Intellectual disability & Intellectual disability \\
\hline $\begin{array}{l}\text { High pitched/squeaky } \\
\text { voice }\end{array}$ & High pitched cry & High pitched voice \\
\hline Micrognathia & Micrognathia & Micrognathia \\
\hline $\begin{array}{l}\text { Low set and/or posteriorly } \\
\text { rotated ears }\end{array}$ & Low set ears & Normal set rotated ears \\
\hline $\begin{array}{l}\text { Down-turned corners of the } \\
\text { mouth }\end{array}$ & $\begin{array}{l}\text { Down-turned corners of the } \\
\text { mouth }\end{array}$ & Normal mouth \\
\hline Clinodactyly & Clinodactyly (rare cases) & No clinodactyly \\
\hline Hypoglycaemia & No data & Hypoglycaemia \\
\hline Prominent forehead & Normal forehead & Prominent forehead \\
\hline Triangular face & $\underline{\text { Round face }}$ & Triangular face \\
\hline $\begin{array}{l}\frac{\text { Feeding difficulties }}{\text { and/or low body mass }} \\
\text { index }\end{array}$ & Normal feeding & Failure to thrive \\
\hline$\underline{\text { Relative macrocephaly }}$ & Microcephaly & Microcephaly \\
\hline Body asymmetry & No asymmetry & No asymmetry \\
\hline Normal nose & $\begin{array}{c}\text { Broad nasal bridge with } \\
\text { prominent nasal root }\end{array}$ & Normal nose \\
\hline No data & Abnormal dermatoglyphics & No data \\
\hline No palatal alteration & High palatal arch & No palatal alteration \\
\hline No hypertelorism & Hypertelorism & No hypertelorism \\
\hline Normal eyelids & Epicanthal folds & Normal eyelids \\
\hline Normal eyes & $\begin{array}{c}\text { Downslanting palpebral } \\
\text { fissures }\end{array}$ & Normal eyes \\
\hline No data & $\begin{array}{l}\text { Small hands with thin and } \\
\text { long fingers }\end{array}$ & Short fingers \\
\hline No sandal gap & Sandal gap in both feet & Normal feet \\
\hline
\end{tabular}

From darkest to lightest grey, the features are highlighted as follows: common features between (1) SRS, CdCS and the patient, (2) SRS and CdCS, (3) SRS and the patient and (4) CdCS and the patient. IUGR intrauterine growth retardation, PNGR post-natal growth retardation. Underlined features are those most specific to each syndrome

The majority of chromosome $5 p$ deletions are associated with CdCS, but a del(5p) karyotype does not necessarily indicate CdCS [20, 23]. According to various different mapping studies using a strategy of "phenotype dissection", some regions of the short arm of chromosome 5 have been associated with specific features which define certain aspects of the CdCS phenotype. Based on those studies, the critical factor responsible for the CdCS phenotype is considered to be the deletion located at $5 \mathrm{p} 15.2$, as haploinsufficiency of genes in this region is assumed to be associated with changes in facial features and severe mental retardation, as well as general CdCS features $[19,20,22,24]$. Patients presenting the characteristic cat-like cry, the origin of the name of the 
syndrome, carry a deletion that includes a region proximal to $5 \mathrm{p} 15.3$ and distal to $5 \mathrm{p} 15.2$ [24, 25]. Different genes located within this region have been proposed to be responsible for the feature, namely, $U B E 2 Q L 1 /$ FLJ28076 (5p15.31) and MARCH6/TEB4 (5p15.2) [26]. Surprisingly, the deletion of the patient we report encompasses both candidate genes, but she did not have the classical cry, just a high-pitched voice. Coincidentally, there is another CdCS case described in the literature in which the patient did not have high pitched cry but did have a high-pitched voice. He had a 5p15.2 deletion, similar to our patient, and they share other clinical characteristics such as growth delay, slightly small chin, hypotonia and speech delay [22].

The most distal part of $5 \mathrm{p}$, the $5 \mathrm{p} 15.3$ band, has been reported to be related to speech delay [27]. In that region, more precisely at $5 \mathrm{p} 15.33$, studies have located the SLC6A3 gene, which encodes an amine transporter responsible for dopamine reuptake. Curiously, an excess of dopamine has been associated with problems in speech due to its major role in fine motor movements and the fact that speech requires very accurate coordination of very diverse small muscles [28]. The patient we describe has speech problems, probably because of a defect in the in the larynx with vocal fold atrophy. Notably, the $S L C 6 A 3$ gene lies within the patient's deletion, and that may explain the speech problems.

In addition, intellectual disability has been associated with a region at $5 \mathrm{p} 15.2$ [24], where the CTNND2 gene is located [29]. This gene encodes a protein which plays a critical role in neural development, particularly in the formation and/or maintenance of dendritic spines and synapses [30]. In the same cytogenetic band, there is another region which seems to be responsible for the facial dysmorphism $[19,22,31]$. Further, alterations in SEMA5A (5p15.31) [32] and CDH18 (5p14.3), CDH10 (5p14.2) and $C D H 9$ (5p14.1) [33] also disrupt normal brain development; whereas autism spectrum and social communication disorders have been associated with the 5p14.1 cytogenetic band [34]. Like many other cases and as described above, our patient has intellectual disability, not having achieved the milestones for her age. Even though $\mathrm{CDH}$, $\mathrm{CDH} 10$ and $\mathrm{CDH} 18$ genes are supposed to be involved in intellectual disability, they may be not so critical because they do not lie within the region of the patient's deletion. On the contrary, CTNND2 and SEMA5A are in the deleted region and in consequence they may be responsible for this feature. On the other hand, autism is not one of the girl's characteristics, perhaps due to the fact that the aforementioned region does not lie within the deletion. The $\mathrm{CDH} 9$ gene is located in the band related to autism, and hence, it could be responsible for this feature apart from intellectual disability.
Some of these phenotypic features are in common with those of SRS (Table 1). In fact, the patient we describe has four out of the six cardinal characteristics [6] of SRS and lacks other important features of CdCS (high pitched cry, rounded face). What is more, the syndromes share some cardinal features, making it difficult to reach an accurate clinical diagnosis when they are present in a patient. On the other hand, according to the recent reviews $[9,15]$, ours is the first report of a patient with SRS carrying a deletion at 5q. As suggested above, the reason for the absence of these cardinal CdCS features could be that the chromosomal regions involved in these signs are not deleted in our patient. Nevertheless, as previously suggested by other authors [26], it is important to underline the great variability in each feature as each individual trait is not caused by alterations in a single gene. Detailed molecular analysis of more patients with well-established clinical features is necessary to identify the role of the genes responsible for the CdCS.

In brief, overlapping clinical manifestations of different disorders can lead to a misdiagnosis that could be avoided with more detailed molecular testing. Specifically, deletions at $5 p$ should be considered in clinical SRS patients with negative results for chromosome 11 and 7 alterations.

On the other hand, given the importance of correlating the deleted regions at $5 \mathrm{p}$ and the clinical features associated with CdCS, some chromosomal maps have been developed. Nevertheless, more molecular karyotyping studies would help identify precise genomic coordinates responsible for each feature of the syndrome.

\section{Additional file}

Additional file 1: Figure S1. FISH images of the index, her father and her mother. DX0164-I code is for the patient, DX0164-P for the father and DX0164-M for the mother. A, C, E pictures are from interphase nuclei and $\mathrm{B}, \mathrm{D}, \mathrm{F}$ from chromosomes in metaphase. One green signal (5p15) and two red signals (CSF1R probe) are visible in the index, suggesting a deletion of the 5 p15 region. Both parents presented a normal result (2G2R) for FISH on chromosome 5. (TIF $235 \mathrm{~kb}$ )

\section{Abbreviations}

5p-: Deletion on the short arm of chromosome 5; aCGH: Microarray-based Comparative Genomic Hybridization; CdCS: Cri-du-Chat Syndrome; CNV: Copy Number Variation; DMR: Differentially Methylated Region; FISH: Fluorescence In Situ Hybridization; IUGR: IntraUterine Growth Retardation; NH-CSS: Netchine-Harbison SRS Clinical Scoring System; PNGR: PostNatal Growth Retardation; SD: Standard Deviation; SRS: SilverRussell Syndrome; upd(7)mat: Maternal uniparental disomy for chromosome 7

\section{Acknowledgements}

We thank the patient and her parents for their participation in the study.

\section{Funding}

The costs of the publication and molecular analyses of this research were funded by grants from Instituto de Salud Carlos III (Institute of Health Carlos III) of the Spanish Ministry of Economy and Competitiveness, co-financed by the European Regional Development Fund (PI16/00073), the Department of 
Health of the Basque Government (GV2016111105; GV2017111040), and the University of the Basque Country UPV/EHU (PIF17/29).

\section{Availability of data and materials}

All data are available for the scientific community, including raw genetic data: requests should be sent directly to the corresponding author.

\section{Authors' contributions}

GPN conceived the project. AP designed the molecular approach. YV and JE$D$ performed the molecular studies of the syndromes. LG-N designed and carried out FISH analysis. GPN, AP, YV, JE-D and LG-N collaborated in the molecular analyses. IL, NG and BG participated in the recruitment, clinical information acquisition of the patient and parents and wrote the clinical description and discussion. $\mathrm{Y}$ and JE-D designed and wrote the first draft with molecular aspects in collaboration with LG-N. AP and GPN combined both clinical and molecular sections and prepared the first complete draft. All authors included modifications and suggestions to the initial version which were compiled by $\mathrm{Y}$ and GPN. All authors read and approved the final version of the manuscript.

\section{Ethics approval and consent to participate}

All procedures followed met the ethical standards of the responsible committee. The present study was approved by the Basque ethics committee (PI2017018). Genetic analysis was performed after written informed consent from both parents.

\section{Consent for publication}

Consent to publish clinical data and photos of the patient was obtained from both parents of the minor.

\section{Competing interests}

The authors declare that they have no competing interests.

\section{Publisher's Note}

Springer Nature remains neutral with regard to jurisdictional claims in published maps and institutional affiliations.

\section{Author details \\ 'Rare Diseases Research Group. Molecular (Epi)Genetics Laboratory, BioAraba Health Research Institute, OSI Araba University Hospital, Vitoria-Gasteiz, Araba, Spain. 'Laboratory of Pharmacy and Pharmaceutical Technology, Faculty of Pharmacy, University of the Basque Country (UPV/EHU), Vitoria-Gasteiz, Araba, Spain. ${ }^{3}$ Service of Genetics, BioCruces Bizkaia Health Research Institute, Hospital Universitario Cruces, Barakaldo, Bizkaia, Spain. ${ }^{4}$ Service of Pediatric Neurology, BioAraba Health Research Institute, Hospital Universitario Araba-Txagorritxu, Vitoria-Gasteiz, Araba, Spain.}

Received: 27 June 2018 Accepted: 3 December 2018 Published online: 27 December 2018

\section{References}

1. Silver HK, Kiyasu W, George J, Deamer WC. Syndrome of congenital hemihypertrophy, shortness of stature, and elevated urinary gonadotropins. Pediatrics. 1953:12:368-76.

2. Russell A. A syndrome of intra-uterine dwarfism recognizable at birth with cranio-facial dysostosis, disproportionately short arms, and other anomalies (5 examples). Proc R Soc Med. 1954;47:1040-4.

3. Wakeling EL, Brioude F, Lokulo-Sodipe O, O'Connell SM, Salem J, Bliek J, et al. Diagnosis and management of Silver-Russell syndrome: first international consensus statement. Nat Rev Endocrinol Nature Publishing Group. 2017;13: 105-24.

4. Toutain A. Silver-Russell syndrome [Internet]. 2007. Available from: https:// www.orpha.net/consor/cgi-bin/OC_Exp.php?Lng=EN\&Expert=813

5. Duncan PA, Hall JG, Shapiro LR, Vibert BK. Three-generation dominant transmission of the Silver-Russell syndrome. Am J Med Genet. 1990;35:245-50

6. Azzi S, Salem J, Thibaud N, Chantot-Bastaraud S, Lieber E, Netchine I, et al. A prospective study validating a clinical scoring system and demonstrating phenotypical-genotypical correlations in Silver-Russell syndrome. J Med Genet. 2015;52:446-53.
7. Brioude F, Oliver-Petit I, Blaise A, Praz F, Rossignol S, Le Jule M, et al. CDKN1C mutation affecting the PCNA-binding domain as a cause of familial Russell Silver syndrome. J Med Genet. 2013;50:823-30.

8. Begemann M, Zirn B, Santen G, Wirthgen E, Soellner L, Büttel H-M, et al. Paternally inherited IGF2 mutation and growth restriction. N Engl J Med. 2015:373:349-56.

9. Tümer Z, López-Hernández JA, Netchine I, Elbracht M, Grønskov K, Gede LB, et al. Structural and sequence variants in patients with Silver-Russell syndrome or similar features-curation of a disease database. Hum Mutat. 2018:39:345-64

10. Liu D, Wang Y, Yang X-A, Liu D. De novo mutation of paternal IGF2 gene causing Silver-Russell syndrome in a sporadic patient. Front Genet. 2017:8:105

11. Abi Habib W, Brioude F, Edouard T, Bennett JT, Lienhardt-Roussie A, Tixier F, et al. Genetic disruption of the oncogenic HMGA2-PLAG1-IGF2 pathway causes fetal growth restriction. Genet Med. 2017;20:250-8.

12. De Crescenzo A, Citro V, Freschi A, Sparago A, Palumbo O, Cubellis MV, et al. A splicing mutation of the HMGA2 gene is associated with Silver-Russell syndrome phenotype. J Hum Genet. 2015;60:287-93.

13. Eggermann T, Begemann M, Binder G, Spengler S. Silver-Russell syndrome: genetic basis and molecular genetic testing. Orphanet J Rare Dis. 2010:5:19.

14. Giabicani E, Netchine I, Brioude F. New clinical and molecular insights into Silver-Russell syndrome. Curr Opin Pediatr. 2016;28:529-35.

15. Fokstuen $\mathrm{S}$, Kotzot D. Chromosomal rearrangements in patients with clinical features of Silver-Russell syndrome. Am J Med Genet Part A. 2014:164:1595-605

16. Lejeune J, Gautier M, Lafourcade R, Berger R, Turpin R. Trois cas de délétion partielle du bras court d'un chromosome 5. Ann Génétique. 1963;7:7-12.

17. Higurashi M, Oda M, lijima K, lijima S, Takeshita T, Watanabe N, et al. Livebirth prevalence and follow-up of malformation syndromes in 27,472 newborns. Brain and Development. 1990;12:770-3.

18. Niebuhr E. The cri du chat syndrome: epidemiology, cytogenetics, and clinical features. Hum Genet. 1978;44:227-75.

19. Mainardi PC, Perfumo C, Calì A, Coucourde G, Pastore G, Cavani S, et al. Clinical and molecular characterisation of 80 patients with $5 p$ deletion: genotype-phenotype correlation. J Med Genet. 2001:38:151-8.

20. Church DM, Bengtsson U, Nielsen KV, Wasmuth JJ, Niebuhr E. Molecular definition of deletions of different segments of distal $5 p$ that result in distinct phenotypic features. Am J Hum Genet. 1995;56:1162-72.

21. Cerruti MP. Cri du Chat syndrome. Orphanet J Rare Dis. 2006;1:33.

22. Church DM, Yang J, Bocian M, Shiang R, Wasmuth JJ. A high-resolution physical and transcript map of the cri du chat region of human chromosome 5p. Genome Res. 1997;7:787-801.

23. Gu H, Jiang J, Li J, Zhang Y, Dong X, Huang Y, et al. A familial Cri-du-chat/ $5 p$ deletion syndrome resulted from rare maternal complex chromosomal rearrangements (CCRs) and/or possible chromosome $5 p$ chromothripsis. PLoS One. 2013:8:e76985.

24. Overhauser J, Huang X, Gersh M, Wilson W, Mcmahon J, Bengtsson U, et al. Molecular and phenotypic mapping of the short arm of chromosome 5: Sublocalization of the critical region for the cri-du-chat syndrome. Hum Mol Genet. 1994:3:247-52.

25. Gersh M, Goodart SA, Pasztor LM, Harris DJ, Weiss L, Overhauser J. Evidence for a distinct region causing a cat-like cry in patients with $5 p$ deletions. Am J Hum Genet. 1995;56:1404-10.

26. Wu Q, Niebuhr E, Yang H, Hansen L. Determination of the "critical region" for cat-like cry of Cri-du-chat syndrome and analysis of candidate genes by quantitative PCR. Eur J Hum Genet. 2005;13:475-85.

27. Baccichetti $C$, Lenzini $E$, Artifoni $L$, Caufin D, Marangoni P. Terminal deletion of the short arm of chromosome 5. Clin Genet. 1988;34:219-23.

28. Lan J, Song M, Pan C, Zhuang G, Wang Y, Ma W, et al. Association between dopaminergic genes (SLC6A3 and DRD2) and stuttering among Han Chinese. J Hum Genet. 2009:54:457-60.

29. Medina M, Marinescu RC, Overhauser J, Kosik KS. Hemizygosity of deltacatenin (CTNND2) is associated with severe mental retardation in cri-duchat syndrome. Genomics. 2000;63:157-64.

30. Turner TN, Sharma K, Oh EC, Liu YP, Collins RL, Sosa MX, et al. Loss of $\delta$ catenin function in severe autism. Nature. 2015;520:51-6.

31. Rodríguez-Caballero A, Torres-Lagares D, Rodríquez-Pérez A, SerreraFigallo M-A, Hernández-Guisado J-M, Machuca-Portillo G. Cri du chat syndrome: a critical review. Med Oral Patol Oral Cir Bucal. 2010;15: $473-8$. 
32. Simmons AD, Püschel AW, McPherson JD, Overhauser J, Lovett M. Molecular cloning and mapping of human semaphorin $\mathrm{F}$ from the Cri-du-chat candidate interval. Biochem Biophys Res Commun. 1998;242:685-91.

33. Barber JCK, Huang S, Bateman MS, Collins AL. Transmitted deletions of medial $5 p$ and learning difficulties; does the cadherin cluster only become penetrant when flanking genes are deleted? Am J Med Genet A. 2011;155A: 2807-15.

34. Espirito Santo LD, Moreira LMA, Riegel M. Cri-Du-chat syndrome: clinical profile and chromosomal microarray analysis in six patients. Biomed Res Int. 2016;2016:5467083.

35. Nguyen JM, Qualmann KJ, Okashah R, Reilly A, Alexeyev MF, Campbell DJ. $5 p$ deletions: current knowledge and future directions. Am J Med Genet C Semin Med Genet. 2015;169:224-38.

Ready to submit your research? Choose BMC and benefit from:

- fast, convenient online submission

- thorough peer review by experienced researchers in your field

- rapid publication on acceptance

- support for research data, including large and complex data types

- gold Open Access which fosters wider collaboration and increased citations

- maximum visibility for your research: over $100 \mathrm{M}$ website views per year

At $\mathrm{BMC}$, research is always in progress.

Learn more biomedcentral.com/submissions 